\title{
Secondhand Goods, Firsthand Knowledge: An Organizational Structure Exercise At The Local Flea Market
}

Monika K. Renard, Florida Gulf Coast University

William J. Ritchie, James Madison University

Charles J. Fornaciari, Florida Gulf Coast University

\begin{abstract}
We developed a unique and enjoyable field trip exercise to challenge students to identify various organizational structures and their properties and dimensions present in the local flea market. Drawing on students' review of common organizational structures, i.e., simple, functional, multidivisional, and network, this exercise requires that individuals or small groups of students visit a local flea market to observe and analyze the numerous organizational structures apparent. Students then use a given report format to identify: the properties of organizations; distinct organizational structures on varying levels of analysis (the market as a whole, areas of specialization, and vendors); and the dimensions seen in organizations (specialization, span of control, formalization, and centralization). In-class discussion of the topic, using discussion questions provided, further clarifies the concepts that students viewed in practice at the flea market.
\end{abstract}

Keywords: management, strategic management, organizational structure, exercise, student activity.

\section{INTRODUCTION}

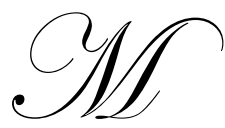

anagement courses, especially strategic management courses taught at the undergraduate level, are often tasked with exposing students to a number of concepts or skills that they may not have had enough organizational membership experience to appreciate adequately (Short \& Ketchen, 2005). (As strategy professors, we focus on that context, though other management contexts are equally valuable). Some of the content in strategic management, for example, like competitive advantage, generic strategies, and market dynamics, are often taught using techniques such as computer-based simulations and case discussions to help students grasp the concepts better conceptually and perhaps affectively. Indeed, a review of leading management pedagogy journals that routinely publish exercises or activities, such as the Journal of Management Education and Simulation and Gaming, indicates how frequently strategy-course-focused articles deal with improving learning via the use of either simulations or the case method (for example, in the past five years the following articles have been published: McKone \& Bozewicz, 2003; Chang, Lee, Ng, \& Moon, 2003; Doh, 2004; Casile \& Wheeler, 2005; Rollag \& Parise, 2005; Schumann, Scott, \& Anderson, 2006; Banning, 2003; Joshi, Davis, Kathuria, \& Weidner, 2005; Bowden, Clark, Collins, Gibb, Kearins, \& Pavlovich, 2006; Smith, 2003).

By and large, however, strategic management courses still offer fewer student exercises when compared to courses such as organizational behavior (Joshi, Davis, Kathuria, \& Weidner, 2005). In addition, upon closer examination, some critical theoretical concepts relied upon in strategic management (and other management courses) have received little in-depth coverage in the journals - organizational structure is certainly the case here. We suspect this is due in part to the difficulty in presenting these often highly abstract, yet operational, ideas to students without significant real world experience. 
The concept of organizational structures - covered to some extent in principles of management, organizational behavior, and strategic management, and to a greater extent in organizational theory course (which unfortunately seems to be disappearing in many undergraduate business programs) - is particularly difficult to convey to students in an engaging manner. Even a cursory glance at some leading strategic management textbooks (David, 2006; Hill \& Jones, 2006; Thompson, Strickland, \& Gamble, 2008; Wheelen \& Hunger, 2007), for example, reveals an ongoing struggle among those authors and from edition to edition to present the elements of structure in an accessible and engaging manner. As a result, the lack of engaging exercises may lead instructors to teach students about various structures using somewhat uninspiring textbook flow charts and organizational diagrams. Further, the few journal articles that provide student exercises in organizational structure, though valuable for some purposes, could be augmented by exercises that are more hands-on. For example, Brumagim (1995) presents a classroom exercise designed to help students understand Thompson's (1967) three types of organizational interdependencies. Harvey and Morouney (1998) present an in-class exercise based on a case history of Club Med to help students understand the concepts of differentiation, integration, and control. Finally, Short and Ketchen (2005) provide a twoparagraph suggestion that teachers use the fable "The Horse and the Groom" to illustrate organization structure concepts. We realize that many professors are excellent at developing their own very creative exercises, but those are not reported in enough frequency to be useful to others of us who are seeking new, innovative ideas. Consequently, published pedagogies to teach organizational structure concepts may be somewhat limited in their breadth, richness and appeal.

Furthermore, it is likely that even students with a broad range of work experience have not observed a variety of possible organizational structures first-hand, or have not recognized them as such. We find this disturbing, given the critical impact that structure has in many areas of an employee's life, as well as Joshi, Davis, Kathuria, and Weidner's (2005) emphasis on the importance of experiential methods in the teaching of strategic management, developing student understanding of theoretical concepts, and thereby engaging them in the learning process.

One potential hands-on means of enriching students' understanding of organizational structures is to embark on field trips to various organizations in an effort to expose them to differing structures. But given the large number of organizations it would be necessary to visit to do so, i.e., four organizations just to cover the basic structures of simple, functional, multi-divisional form (M-Form), and network, this would be logistically cumbersome to coordinate and implement.

We provide a unique and enjoyable exercise that attempts to overcome both deficiencies - a limited number of on-site experiences, and deep coverage of structural elements through the few published classroom exercises - by having students experience multiple real-world organization structures in a familiar context. The common local flea market offers a rich environment for the study of organizations. It is one that can be used to illustrate the practical application of the definition of an organization, the dimensions of structure, and their use in determining the four basic organizational structures. Using this engaging exercise, the students consider the flea market as an organizational whole and its components, including individual vendors, to view, report on, and discuss basic organizational structure issues. The exercise provides students with an excellent opportunity to apply critical thinking skills, observe, describe and then discuss the basic principles of organizations and organizational structure using Flea Markets as an example.

This field-trip is a useful activity to help students in a variety of courses learn to recognize basic organizational structure concepts in classes principles of management, organizational behavior, and organizational theory. It would be especially helpful in strategic management classes where students often need a review of organizational structure concepts that may have been covered previous classes. Further, since the exercise requires students to discover by observation and by questioning flea market members, it may be useful to use as a field-based research project, where students develop some basic research skills.

It enables students to understand textbook theories by experiencing a practical application, and may contribute to positive student motivation, a factor in instructional effectiveness (Burke \& Moore, 2003). First, we will discuss the logic behind using flea markets as the basis of the exercise, followed by an overview of the properties of an organization, the four basic forms that organizational structure can take, and the dimensions of 
structure. We then present the exercise, including instructions, basic debriefing issues, measures of the exercise's effectiveness, and potential variations on the exercise.

\section{WHY FLEA MARKETS?}

Flea markets are common throughout the United States. For example, just in our state there are 86 flea markets listed in the Flea Market Guide. The number of dealers/vendors per flea market ranges from 20 to 1,400, with the larger markets enjoying as many as 500,000 visitors per year (www.fleamarketguide.com). Because they are ubiquitous, are readily accessible, and may present varying organizational structures, flea markets present a convenient, appropriate, and enjoyable choice for this exercise. Students travel to and explore a place that connects people from all walks of life in a mass of humanity. The activity requires them to see the flea market as an interconnected system of people and organizations with deep underlying structures and processes. It liberates students from the confines of the traditional classroom and places them into an active learning environment.

The goal of this exercise is to provide faculty with a teaching tool to present in a hands-on manner an idea that is often viewed in the abstract-organization structure. We are sure that some instructors will wish to use their own elements of organization structure as they use and adapt this exercise for their own needs. However, we feel that it is worthwhile to present our thinking on organizational descriptors, along with the examples, in order to provide a comprehensive package that not only makes our handouts and appendices accessible, but also allows for a self-contained exercise within the manuscript that is immediately ready for classroom application. We feel that this is particularly important given the fact that some strategic management textbooks, such as Thompson, Strickland, and Gamble (2008), have virtually eliminated explorations of organization structure from their pages in recent editions.

\section{PROPERTIES OF AN ORGANIZATION}

Before students can identify organization structures, they need to understand whether they are observing organizations at all. The four properties of an organization as developed by Katz and Gartner (1988) are: intentionality, resources, boundary, and exchange. These can be used to explain the broad context of the flea market organization itself, groupings within the market, and individual vendors. The following discussion provides two examples of what students typically discover for each property when they participate in the exercise.

We differentiate between the overall flea market (the owners/management of the overall market, who rent out spaces to private vendors and provide services for them; and may also use some spaces for their own sales) and the individual vendors (independent sellers who rent a space in the flea market). We give examples of each aspect of structure from the view of the overall flea market and from the view of the independent vendor.

\section{Intentionality}

The intentionality dimension reflects the goals of the founding entrepreneurs, the agents, or founders of the organization. From the perspective of the overall flea market management, the concept of intentionality was evident in one of the key owner's comments regarding the founding of the flea market: “...the Jones family purchased the old truck stop thirteen years ago to start a Flea Market...the family got a good deal on the land...the demise of the truck stop was due to the (addition of an) Interstate highway system." In essence, the Jones' goal was to establish a "Flea Market."

From the perspective of individual vendors, virtually every individual vendor interviewed indicated a specific "intent" and proposed to begin their business at the flea market on a given date, e.g., to clean out surplus merchandise from their main business operations to making extra spending money in preparation for the holidays. 


\section{Resources}

This dimension represents various resource commitments such as tangible assets, human assets, and intellectual capital. From the perspective of the overall flea market management, the flea market property includes human capital, financial capital, and real property (e.g., real estate, equipment, raw materials). The owners of the flea market utilize and provide a variety of resources for their vendors as well. In addition to physical property resources, e.g., awnings, cement walkways, building infrastructure, the overall flea market management provides various services for the vendors, such as change for large denomination currency, access to an ATM, tax reporting forms, and vendor directories. Another service that might be included in the resource category is the enforcement of rules and regulations. For example, flea market managers may instruct a vendor to move his/her goods away from another table that he/she had not rented. Promotion, e.g., newspaper articles and flea market directories, may be classified into the resource category as well.

From the perspective of the individual vendor, each individual kiosk or flea market booth contains specific assets in the form of inventories, financial accounting tools, e.g., calculators, cash registers, and computers, and human assets, e.g. salespeople.

\section{Boundary}

Flea markets have clearly defined barrier conditions between the organization and its environment. The physical boundaries of the overall flea market are readily visible to the casual observer. The most noticeable structural component of the boundary is often a roof that shades vendors and customers from the elements. Entrance into this "shelter" communicates passage from an "outside" environment into the "market area." Other markers for the organizational boundary include perimeter fences, roads and signage. Further, there are established protocols for "outsiders" to remove resources from inside the "boundary," e.g., a transaction involving currency or other valuable items.

On the individual vendor level, boundary is most apparent while viewing the tables and associated kiosks. The casual observer will see various partitions, e.g., tables, temporary walls, tapestries, etc., that separate the vendors from each other as well as from the customers.

\section{Exchange}

The infrastructure of the flea markets facilitates transactions on a number of levels. On the overall flea market level, the transactions can be between flea markets located in different cities or with outside parties, e.g., individuals or other organizations.

On the local level, transactions occur across the borders of subsystems, e.g. between flea market areas, and within the organization, e.g., between individual vendors. The transactions between vendors and the customers are the most common.

Once it is clear that an organization exists, students are tasked to identify its structure.

\section{BASIC ORGANIZATION STRUCTURES}

This exercise provides students with an opportunity to identify the most frequently referenced forms of organizational structure: simple, functional, multi-divisional, and network. Using multiple levels of analysis (overall flea market and individual vendors), students are asked to identify all of these structures in the flea market context. Flea market examples of each basic structure are provided below. 


\section{Simple or Entrepreneurial Structure}

The simple (or entrepreneurial) form has little formal structure, very few or no staff, and most of the power focusing on the founder or chief executive. Management performance in this form is typically based upon the personal, subjective control of the owner (Thain, 1969; Mintzberg, Lampel, Quinn, \& Ghoshal, 2003). In a flea market, each of the individual vendors may represent one business unit. Each booth or kiosk in the flea market is an entrepreneurial venture formed by an individual proprietor for the purpose of satisfying the needs of customers. There may or may not be employees; the proprietor may be responsible for all activities.

\section{Functional Structure}

A functional structure is typically representative of organizations where the entrepreneur has been replaced by a group of managers with diversified skills in specific functional areas, e.g., finance, accounting, marketing, production, information systems, and management (Wheelen \& Hunger, 2007; Thain, 1969). When viewed from the next higher level of analysis, it becomes evident that there is functional differentiation within the various flea market sections. For example, typically there are specially marked areas of the flea market where customers can obtain food and fresh produce. Other flea market sections may include automotive vendors, apparel, or common household goods. Viewed from this level of analysis, the flea market takes on the characteristics of a "functionally structured" organization.

\section{Multi-divisional}

Multi-divisional (M-Form) structure is representative of the organization that is divided into separate operating divisions or strategic business units (SBUs). SBUs are divisions or groups of divisions comprised of independent product/market segments that are given primary responsibility and authority for the management of their own functional areas (Wheelen \& Hunger, 2007; Mintzberg et al., 2003). A flea market can be viewed as a consolidated unit and a division of a holding company. For example, many flea markets are owned by a holding company, e.g., Fleamasters in the state of Florida. Each flea market may be uniquely designed to cater to its respective environment. A manager of a flea market holding company described one flea market location as an "official" flea market, while he termed other flea market holdings as "basic." The "official" flea market offered an air-conditioned environment and "upscale" goods to its patrons, whereas another "basic" flea market sold mostly second-hand, inexpensive goods in an open-air kiosk environment.

\section{Network}

Miles and Snow (1994) suggest four key characteristics of this organization structure. First, instead of holding the production assets in a central location, e.g., functional and divisional forms, the networked organization uses the collective assets of many firms. Second, in a true network organization resource flows are left up to market mechanisms for regulation. Demand and competition regulate the costing and delivery of resources. Third, a very active role is expected of each participant in the network with regard to product enhancement and development. Fourth, network organizations are sometimes vertically integrated companies. It would not be uncommon for the network organization to include companies ranging from the raw material suppliers to the financiers of the production. The flea market derives much of its value from the synergies of multiple independent businesses agreeing to work together. The success or failure of the business members of this "network" is truly determined by market forces.

On the individual vendor level, it is not uncommon to observe vendors referring customers to other businesses in the flea market for value-added services. For example, close ties develop between electronics vendors and others marketing electric power supplies and batteries. Similarly, tire vendors maintain close connections with others selling aluminum alloy rims and tire accessories. The emphasis here is that the individual owners or vendors, representing varied products, are seeking a degree of synergy in their business by loose coupling with others in a form of small business network. The network enables small firms or vendors to act large. In this case, a very small business can draw upon the size and infrastructural amenities of the flea market. 


\section{DIMENSIONS OF ORGANIZATION STRUCTURE}

Research in traditional organizational theory has revealed that most organizations can be evaluated according to the underlying independent dimensions of specialization, span of control, formalization, and centralization (Pugh, Hickson, Hinings \& Turner, 1968; Child, 1972). These dimensions help to describe how activities are structured and authority is concentrated within organizations. In practice, the four different organizational forms identified in the flea market possess varying levels of specialization, spans of control, formalization, and centralization. For illustrative purposes, each of the dimensions will be discussed in the context of the simple and the multidivisional structure. Since all of the dimensions are noted to some extent in both the overall flea market and also the individual level, no specific examples are given. However, on the student handout clues are given for what the students should look for.

\section{Specialization}

This represents the grouping of a similar task or function within the same departmental unit to achieve maximum efficiency. As a simple organizational form, the individual vendor in the flea market has a low level of specialization since multiple tasks are typically performed by the "departmental unit," the sole proprietor/owner. By contrast, the multidivisional form will possess the largest degree of specialization since various areas of the flea market such as apparel, produce, and the like are grouped according function.

\section{Span Of Control}

Span of control represents the number of subordinates that report to a given manager. Organizations with a wide "span" of control typically have a large number of subordinates reporting to a single manager. Organizations with multiple levels, e.g. "tall" organizations, possess a relatively small number of subordinates reporting to a given manager and are exemplary of narrow spans of control. In the context of the flea market, the simple organizational forms typically posses narrow spans of control, as few or no individuals report to the founding entrepreneur. In contrast, the multidivisional form possesses a wide span of control, where multiple individuals may report to division managers.

\section{Formalization}

The degree of formalization is the extent to which there are formal rules, policies, and procedures to ensure that individuals and departments coordinate highly differentiated tasks. Highly formalized organizations (for example, banking institutions) typically have well defined policy manuals that describe the approved method for handling most situations encountered by organizational units. In the flea market context, the simple structure form typically possesses a low level of formalization. In this case, since the individual owner has very few subordinates the necessity for documentation of formal rules, procedures, and communication is limited. However, with its multiple organizational layers the multidivisional form must formalize specific operating procedures to ensure cohesiveness in organizational units that may be distanced from headquarters.

\section{Centralization}

Concentration represents the degree to which authority in the organization is concentrated in the upper levels of management. In a centralized organization a few top-level managers are responsible for the majority of key organizational decisions. In a decentralized organization, management decision-making authority is spread widely among various organizational units. In the context of the flea market, the simple forms typically possess a high degree of centralization since the founding entrepreneur will often exercise his/her authority in all organizational decisions. However, the multidivisional form will possess a comparably lower level of centralization, since the decision-making authority in these forms is often delegated to sub-units in the organization. 


\section{EXERCISE INTRODUCTION}

This exercise requires that individuals or groups of students visit the local flea market during active business hours, preferably on a Saturday or Sunday when it is busiest. Prior to their visit, students should remind themselves about the properties of organizations (intentionality, resources, boundary, and exchange), the basic organizational structures (simple, functional, multi-divisional, and network), and the dimensions of organizations (specialization, span of control, formalization, and centralization) as presented in class (and earlier in this paper). They should also prepare the materials that they will take with them to analyze the flea market.

Through observation and/or questioning of vendors, students are required to identify: (a) for the market as a whole, (b) areas of the market, and (c) individual vendors/stalls:

- $\quad$ which of the properties of an organization are displayed;

- which one of the four basic organizational structures exist; and

- $\quad$ which level of each dimension is displayed

\section{Initial Instructor Preparation}

Instructors should first identify any flea markets they wish students to analyze prior to the introduction of the exercise. The names and addresses of the flea markets are often available through the local telephone book or through World Wide Web sites such as the Flea Market Guide mentioned earlier (http://www.fleamarketguide.com/). It is important for instructors to visit the flea markets personally beforehand to familiarize themselves with what students are likely to encounter and to explicitly limit students to visiting those markets they deem most appropriate for the learning goals of the exercise. Optionally, the instructor may wish to treat this exercise as an "organization visit" and connect with the people on site to help ensure success, and perhaps have the management send a letter or post a note to expect the students.

Instructors should obtain vendor directories and personally collect examples of the aspects of organizations that are covered by this exercise. We suggest that instructors answer all of the questions on the student handout for themselves in their visit to the flea market(s), so that they will have specific examples for the debriefing session. Instructors should also consider the discussion questions they will ask to assure that they have answers specific to each of those flea markets.

\section{Introducing the Exercise in the Classroom}

This exercise is typically used in the middle portion of a semester-long undergraduate strategy class-concurrent with the time when most strategic management textbooks introduce the concepts relating to strategy implementation. We envision that it would also be used in a similar fashion in other courses where organizational structure is covered such as organizational theory, organizational design and change, and so on. We typically allow between 30 and 45 minutes to give an introduction to the exercise, discuss the properties of an organization, the organizational structures they take, and the dimensions of the structures (see the preceding discussion of these components). It is important to impress students with the need for them to review this material before they visit a flea market.

As part of this discussion we give students the handout "A Strategic Management Exercise at the Local Flea Market" (see Appendix A). We explain to students that their goal is identify various structures present in the flea market as a whole entity, distinct areas (e.g., a food court), and individual vendors. Students are informed that they should use the format suggested in the handout for collecting their data. The handout is divided into several sections. The first page is an overview of the exercise and its general directions. Page two is the "Field Study Report Form," which is the actual form that students use to prepare each of their observations (e.g., each vendor or area). As the first page of the handout's directions indicate, we advise students that they will need to make six copies of this form - one copy for each observation they will make. Pages three and four are "Clues" sheets that are designed to be taken along by the students on their trips, since we do not envision that students would be willing to carry their 
textbooks with them on this assignment. The clues sheets provide questions for students to consider the main elements under observation (properties and structures), along with a matrix table on page 4 that explicitly asks the students to compare the "typical" organizational structure and its dimensions to their own observations.

After the exercise has been introduced in class, we typically take 5-10 minutes to divide the students into groups of three or four (or you may wish to allow the students to do this exercise individually). Students can either be assigned to a specific flea market or allowed the freedom to choose since a number of students may already have preferred flea markets that they regularly visit. Students should be informed that they will need to budget about one to two hours for data gathering at the flea market.

Finally, we also set a time limit for when the exercise is to be completed, e.g., two weeks hence, and set an appropriate date for when their completed "Field Study Report Forms" (six forms per student/team) should be brought to class for discussion.

\section{DEBRIEFING THE EXERCISE}

The instructor may wish to allocate 30 minutes or more to the debriefing depending on the size of the class. We often find that the students are well-prepared for the discussion. Though we only require that students submit six completed "Field Study Report Forms" to receive credit for the project, we often find that they have gone much further in their work. Typically their submissions are typed and bound, with the report forms being relegated to "appendix" status within their products. We sometimes get additional materials from students from their flea market visits (e.g., business cards and brochures) used to support or illustrate their findings.

Figure 1 lists the questions we usually employ to debrief the exercise, though we imagine that other instructors will wish to change and modify them to suit their own needs. Typically, students enjoy a comparison and contrast among their findings of the structures. They especially appreciate an exploration of why some students had different results. A key component of our debriefing session is having one group discuss the flea market as a whole while asking another group discuss areas of specialization within the market. Finally, we have subsequent groups identify a vendor and the vendor's structure and dimensions, until each group has had a chance to report and as many different structural forms as possible have been identified.

\section{Figure 1. Typical Exercise Debriefing Questions}

1. Is the flea market an organization? Why?

2. Did you observe specialized areas within the flea market?

3. Which of the organizational forms (simple, functional, multi-divisional, and network) was most easily identified during your time at the flea market?

4. Which of the organizational forms was most commonly found at the flea market? Why?

5. Which of the organizational forms was least commonly found at the flea market? Why?

6. Which of the organizational forms was either difficult to identify or was not identified during your study? Why was it difficult to identify?

7. Compare your findings to the Taxonomy of Organizational Forms and Dimensions of Structure (Table A). Did you notice any differences between your findings and the chart? Why do you think those differences exist?

8. Did you notice any instances where an organizational structure was observed more than once at the flea market, yet each instance of the form had different structural dimensions? What can you conclude about organization forms based on this?

\section{ASSESSMENT OF THE EXERCISE'S EFFECTIVENESS}

We have been using this exercise within our undergraduate strategic management courses, with approximately 100 students participating to date. Those students who have participated in the exercise routinely report back on its efficacy in helping them to understand deeply the often abstract concepts of organizational 
structure. Further, they often comment on how engaging they find the exercise, which we suspect in large part is due to the exercise's ability to actively connect them to an environment that many often enjoy already - the flea market.

Given the positive anecdotal reports, the authors also conducted an exploratory post-hoc survey of students completing this exercise at the end of a recent semester to evaluate its effectiveness as a teaching tool. Though the number of students surveyed was limited to one recent class and so is small, the results are suggestive, nonetheless.

We used an adaptation of Davis' (1989) constructs of "perceived usefulness" to survey students' overall perceptions of the usefulness of this exercise. We asked them 13 questions on a five-point Likert-type scale ranging from 1 (strongly disagree) to 5 (strongly agree). Students reported that this exercise "enhanced (their) learning experience in class" $(\mathrm{Q} \# 6$, mean $=4.34)$, that it helped them to better understand the concept of organizational structure $(\mathrm{Q} \# 3$, mean $=4.10)$, and that they had greater understanding of the concept of organizational structure due to the exercise $(\mathrm{Q} \# 9$, mean $=4.23)$. Students also reported that this exercise "helped (them) to see how concepts in the classroom apply in the real world" (4.59). Table 1 is the reports of those survey results from our students about the exercise.

Table 1. Student Survey Responses to the "Flea Market Exercise" (FME)

\begin{tabular}{|c|c|c|c|c|c|}
\hline & $\mathrm{N}$ & Minimum & Maximum & Mean & $\begin{array}{c}\text { Std. } \\
\text { Deviation }\end{array}$ \\
\hline 1. It was relatively easy to complete the FME & 22 & 4 & 5 & 4.32 & 0.477 \\
\hline 2. The FME was easy to understand & 22 & 3 & 5 & 4.09 & 0.684 \\
\hline $\begin{array}{l}\text { 3. The FME helped me to better understand the concept of } \\
\text { organizational structure }\end{array}$ & 21 & 2 & 5 & 4.10 & 0.700 \\
\hline $\begin{array}{l}\text { 4. It was easy for me to see the connection between the FME } \\
\text { and strategic management concepts covered in this course }\end{array}$ & 22 & 3 & 5 & 4.18 & 0.664 \\
\hline 5. The FME was a useful exercise & 22 & 3 & 5 & 4.18 & 0.588 \\
\hline 6. The FME enhanced my learning in this class & 22 & 3 & 5 & 4.34 & 0.565 \\
\hline $\begin{array}{l}\text { 7. Field-trip exercises such as the FME are a useful learning } \\
\text { tool }\end{array}$ & 22 & 3 & 5 & 4.45 & 0.671 \\
\hline $\begin{array}{l}\text { 8. I wish there were more experiences similar to the FME in } \\
\text { this class }\end{array}$ & 22 & 2 & 5 & 4.23 & 0.869 \\
\hline $\begin{array}{l}\text { 9. I feel that I have a greater understanding of the concept of } \\
\text { organizational structures as a result of completing the FME }\end{array}$ & 22 & 3 & 5 & 4.23 & 0.612 \\
\hline $\begin{array}{l}\text { 10. I would recommend the FME to other business strategy } \\
\text { students }\end{array}$ & 22 & 3 & 5 & 4.41 & 0.666 \\
\hline $\begin{array}{l}\text { 11. The FME enhanced my ability to understand organizational } \\
\text { structures }\end{array}$ & 22 & 3 & 5 & 4.18 & 0.664 \\
\hline $\begin{array}{l}\text { 12. There should be more exercises similar to the FME in this } \\
\text { class. }\end{array}$ & 22 & 3 & 5 & 4.36 & 0.790 \\
\hline $\begin{array}{l}\text { 13. It is helpful to see how concepts in the classroom apply in } \\
\text { the "real world" }\end{array}$ & 22 & 3 & 5 & 4.59 & 0.590 \\
\hline
\end{tabular}

It is interesting to note the uniformly strong responses by the students across all dimensions of the survey. No single item was rated lower than 4.0 on a 5.0 scale their evaluation of the activity, and only two questions (Q\#2 "the FME was easy to understand" and Q\#8 "I wish there were more exercises similar to the FME") had any individual student responses lower than 3.0 on the scale - which we suspect was closely correlated with the often abstract nature of organizational structures themselves. Overall, based on both the informal feedback from the students and their responses on survey, we are confident that the exercise provides a contribution to our students' ability to understand the concept of organizational structures. 


\section{POSSIBLE EXERCISE VARIATIONS AND CONCLUSIONS}

The ultimate goal of this exercise was to enable students to experientially grasp a critical conceptorganization structure - that may be difficult to understand for those without significant amounts of work experience. Further, we believe that additional knowledge is gained through the direct exposure to a variety of organization structures, which is often hard to come by even for students with real world work experience.

As strategy professors we designed this exercise to employ another experiential technique other than the all-to-frequently used case studies and computer simulations found in the strategy classroom. We chose to use flea markets because they can offer a variety of organization forms and their often lively atmospheres enable students to become deeply engaged in the topic, which then lets them understand the material in new and meaningful ways.

We envision that this exercise can easily be adapted to suit many different needs of instructors. For example, it would be interesting potentially to have students compare what they found at the flea market versus the local shopping mall, which tends to be dominated by franchises or subsidiaries of national corporations, but is interspersed with smaller independent establishments. We also envision that other faculty could freely adapt the structural elements (properties, forms, and dimensions) that we have covered here to meet their own needs. Our choice of these three components is closely tied back to our orientations as strategy teachers, but we can imagine that organizational behavior and or organizational design instructors could easily modify the forms for their own purposes.

In summary, this exercise provides an engaging approach to learning what can sometimes be too abstract for students to grasp fully. It illustrates the strategic concepts of organizational properties, organizational structure, and organizational dimensions. By requiring students to recognize and apply these concepts in an entertaining venue familiar to all, we have found this exercise to be effective in facilitating learning of these important strategic building blocks.

\section{APPENDIX A: A Strategic Management Exercise at the Local Flea Market}

Directions for the Assignment

The local flea market is a great place to see many organizational structures in action. Your assignment is to go to the local flea market, either individually or with your team, to identify and describe the various organization structures (simple, functional, multi-divisional, and network) present there. Prepare to spend about two hours at the flea market. As you explore the flea market, consider how many different organizational structures exist. Some of these will be immediately evident (e.g., an individual vendor or the whole flea market itself), while others may be less directly visible.

Review the relevant material in your text relating to organizational structures prior to undertaking this exercise. When observing the variety of organizational structures at the flea market, be sure to consider differing levels of analysis, for example: independent vendors, groups of independent vendors, the flea market, and groups of flea markets. Organize your data collection according to the student handout example below.

Make six copies of the Field Study Report Form and use them to record your observations for each of the organizational structures you see. All organizational structures are present at the flea market. For each one observed, please provide the name and a brief description of the business. Specifically discuss details of each of its four dimensions (specialization, span of control, formalization, and centralization). Your identification and descriptions should be about 1-2 paragraphs per structure. Answer the questions on the Field Study Report Form for each of the structures you identified.

Bring your results with you to class on the assigned day. Be prepared to discuss your findings. Choose one of the following flea markets for this exercise:

1. Name and address of flea market;

2. 2. Name and address of flea market 


\section{ORGANIZATIONAL STRUCTURE OBSERVATIONS-FIELD STUDY REPORT FORM}

Name of vendor or organization

Check level of analysis:

$\square$ Flea Market $\square$ Area

$\square$ Vendor/Stall

Description of the business:

Organizational Property Observed (Discuss for each organization):

$\square$ Intentionality

$\square$ Resources

$\square$ Boundary

$\square$ Exchange

Structure Identified (Check one and describe your choice in one to two paragraphs. Use the back of this sheet if you need more room):
$\square$ Simple
$\square$ Functional
$\square$ Multi-divisional
$\square$ Network

Dimensions of Organizational Structure (Specify the degree to which each of the following applies to the observed structure. In a short phrase next to each item, describe why you think this. Use the back of the sheet if you need more room):

Specialization

Span of Control

$\begin{array}{rrr}\text { Low } & \text { Mod } & \text { High } \\ \square & \square & \square \\ \square & \square & \square \\ \square & \square & \square \\ \square & \square & \square\end{array}$

Formalization

Centralization

\section{FIELD STUDY REPORT CLUES}

\footnotetext{
Part A. Properties of an Organization

1. How did this business become a going concern? (Intentionality)

2. What resources does the business provide or use? (Resources)

3. What are the physical boundaries and structures of this business? (Boundary)

4. Are there exchanges among business areas? (Exchange)

5. Are there exchanges within the organization, e.g., between individual vendors (Exchange)

6. Are there exchanges across the organizational boundary with outside parties, e.g. individuals or other organizations. (Exchange)

7. Which of these exchanges are most commonly seen? (Exchange)

\section{Part B. Structure of an Organization}

8. Does this organization have one identifiable owner with generalist employees, if any? (Simple)

9. Is this organization medium-sized with specialist employees important to its industry, e.g., marketing, selling, accounting? (Functional)

10. Is this organization large with many product lines and functional specialist employees, e.g., a strategic business unit (SBU)? (Divisional)

11. Is this organization one with many activities outsourced and a non-hierarchical arrangement? (Network)

\section{Part C. Dimensions of Organizational Structure}

12. Table " $\mathrm{A}$ " (below) provides a matrix relating the various dimensions with typical organizational structures. Fill in Table "B" with your findings from the flea market visit. What similarities and differences exist between your observations and the traditional taxonomy?
} 
Table A

\begin{tabular}{|c|c|c|c|c|}
\hline \multirow{2}{*}{ Organizational Structure } & Dimension of Structure & \multicolumn{4}{|c|}{ Cormalization } & Centralization \\
\cline { 2 - 5 } & Specialization & Span of Control & Low & High \\
\hline Simple & Low & Low & Moderate & Moderate \\
\hline Functional & Moderate & Moderate & High & Low \\
\hline M-Form & High & Low & Low & Low \\
\hline Network & High & Low &
\end{tabular}

Table B

\begin{tabular}{|c|c|c|c|c|}
\hline \multirow{2}{*}{ Organizational Structure } & Dimension of Structure & Formalization & Centralization \\
\cline { 2 - 5 } & Specialization & Span of Control & & \\
\hline Simple & & & & \\
\hline Functional & & & & \\
\hline M-Form & & & & \\
\hline Network & & & & \\
\hline
\end{tabular}

\section{REFERENCES}

1. Banning, K.C. (2003). The effect of the case method on tolerance for ambiguity. Journal of Management Education, 27(5): 556-567.

2. Brumagim, A.L. (1995). A class exercise highlighting Thompson's three types of organizational interdependencies. Journal of Management Education, 19(4):508-512.

3. Burke, L.A.., \& Moore, J.F. (2003). A perennial dilemma in OB education: Engaging the traditional student. Academy of Management Learning and Education, 2(1): 37-52.

4. Casile, M., \& Wheeler, J.V. (2005). The Magnetic Sentences Industry Game: A competitive in-class experience of business-level strategy. Journal of Management Education, 29(10): 696-713.

5. Chang, J. Lee, M., Ng, K., \& Moon, K. (2003). Business simulation games: The Hong Kong experience. Simulation \& Gaming, 34(9): 367-376.

6. Child, J. (1972). Organizational structure and strategies of control: A replication of the Aston study. Administrative Science Quarterly, 17: 163-177.

7. David, F. (2006). Strategic Management: Concepts and Cases, $11^{\text {th }} \mathrm{ed}$. Upper Saddle River, NJ: PrenticeHall.

8. Davis, F. (1989). Perceived usefulness, perceived ease of use, and user acceptance of information technology. MIS Quarterly, September, 319-339.

9. Doh, J.P. (2004). Reconcilable differences? Incorporating a trade-environment simulation into a management course. Journal of Management Education, 28(12): 806-824.

10. Flea Market Guide. Retrieved July 31, 2007 from (www.fleamarketguide.com).

11. Harvey, C., \& Morouney, K. (1998). Organization structure and design: The Club ED exercise. Journal of Management Education, 22(3):425-429.

12. Hill, C.W., \& Jones, G.R. (2006). Strategic management: Complete, $7^{\text {th }} e d$. New York: Houghton Mifflin, Co.

13. Joshi, M.P., Davis, E. B., Kathuria, R., \& Weidner, C.K. (2005). Experiential learning process: Exploring teaching and learning of strategic management framework through the winter survival exercise. Journal of Management Education, 29(10): 672-695.

14. Katz, J. \& Gartner, W.B., (1988) Properties of emerging organizations. Academy of Management Review, 13(2), 429-441.

15. McKone, K., \& Bozewicz, J. (2003). The Ism Simulation: Teaching integrated management concepts. Journal of Management Education, 27(8): 497-515.

16. Miles, R.E. \& Snow, C.C. (2003), Organizational strategy, structure, and process. California: Stanford University Press. 
17. Mintzberg, H., Lampel, J., Quinn, J.B., \& Ghoshal, S. (2003) The strategy process: Concepts, contexts, cases. $4^{\text {th }}$ ed. Upper Saddle River, N.J.: Prentice Hall

18. Pugh, D.S., Hickson, D.J., Hinings, C.R., \& Turner, C. (1968). Dimensions of organizational structure. Administrative Science Quarterly, 13: 65-105.

19. Rollag, K. \& Parise, S. (2005). The Bikestuff Simulation: Experiencing the challenge of organizational change. Journal of Management Education, 29(10): 769-787.

20. Schumann, P.L., Scott, T.W., \& Anderson, P.H. (2006). Designing and introducing ethical dilemmas into computer-based business simulations. Journal of Management Education, 30(2): 195-219.

21. Short, J.C., \& Ketchen, D.J. (2005). Teaching timeless truths through classic literature: Aesop's Fables and strategic management. Journal of Management Education, 29(6): 816-832.

22. Smith, G.F. (2003). Beyond critical thinking and decision making: Teaching business students how to think. Journal of Management Education, 27(2): 24-51.

23. Thain, D.H. (1969). Stages of corporate development. Ivey Business Journal, Winter.

24. Thompson, J.D. (1967). Organizations in Action: Social Science Bases of Administrative Theory. New York: McGraw-Hill.

25. Thompson, A., Strickland, A.J.; \& Gamble, J.E. (2008). Crafting and Executing Strategy: The Quest for Competitive Advantage: Concepts and Cases, 16th ed. Boston: McGraw-Hill Irwin.

26. Wheelen, T.L. \& Hunger, J.D. (2007). Strategic Management and Business policy, $11^{\text {th }}$ ed. Upper Saddle River, N.J.: Prentice Hall.

\section{NOTES}




\section{NOTES}

